01

\title{
Люминесцентные характеристики низкотемпературной плазмы на основе смеси гелий-глутамин
}

\author{
(C) А.А. Генерал \\ Институт электронной фризики НАН Украины, \\ 88017 Ужгород, Украина \\ e-mail: general.andriy@gmail.com
}

Поступила в редакцию 16.11.2020 г.

В окончательной редакции 22.12.2020 г.

Принята к публикации 25.12.2020 г.

\begin{abstract}
Впервые экспериментально исследованы спектры люминесценции низкотемпературной плазмы импульснопериодического разряда в смеси He-Glu при низких давлениях, не превышающих нескольких десятков Torr. Установлено, что в спектральной области 200-850 nm наблюдаются интенсивные полосы УФ излучения полученных фрагментов молекул глутамина, а именно молекул азота $\mathrm{N}_{2}^{*}\left(C^{3} \Pi_{u} \rightarrow B^{3} \Pi_{g}\right)$, а также излучения монооксидов углерода $\mathrm{CO}^{*}\left(B^{1} \Sigma \rightarrow A^{1} \Pi\right)$ в видимой и инфракрасной областях. Наибольший выход люминесценции молекул фрагментов глутамина достигается при температуре стенок газоразрядной трубки, не превышающей $140^{\circ} \mathrm{C}$.
\end{abstract}

Ключевые слова: молекулы глутамина, аминокислота, моноокид углерода, азот, низкотемпературная плазма, импульсно-периодический разряд, люминесценция.

DOI: $10.21883 /$ OS.2021.04.50773.279-20

\section{1. Введение}

Люминесценция источников низкотемпературной плазмы на галогенидах инертных газов [1] и парах воды [2], которые работают при давлениях от низкого [3-5] до атмосферного [6], является объектом многих научных исследований [1-6]. Также актуальным остается исследование процессов возбуждения при столкновениях электронов низких энергий до $100 \mathrm{eV}$ с биомолекулами в газовой фазе, например, с молекулами глутамина [7].

Изучая спектры фотолюминесценции органических молекул, можно понять ряд фотофизических процессов, происходящих в биологических системах. Например, в работе [8] исследованы спектры лазерно возбужденной фотолюминесценции порошка и водного раствора биомолекулы треонина. Авторами были определены спектральные диапазоны фотолюминесценции данной биомолекулы и максимумы интенсивности полученного излучения.

Авторы работы [9] экспериментально исследовали спектры люминесценции порошка глицина в низкотемпературной плазме импульсно-периодического продольного разряда в рабочих смесях аргон-глицин и гелий-глицин. Было установлено, что в газовом разряде происходит фрагментация глицина на карбоксильную $(-\mathrm{COOH})$ и амино $\left(-\mathrm{NH}_{2}\right)$ группы. Также были идентифицированы основные фрагменты молекулы глицина, которые излучают в спектральной области 200-1000 nm.

Актуальной остается также разработка способов накачки для получения максимальных выходных характеристик излучения низкотемпературной плазмы, которое может быть полезным для некоторых практических применений, например в медицине. Как правило, применяются барьерный, тлеющий и продольный импульснопериодический разряды, которые отличаются не только конструкцией самого излучателя, но также и рабочим давлением и некоторыми другими параметрами. Одними из наиболее перспективных для практического применения являются источники излучения низкотемпературной плазмы, в которых для возбуждения рабочей смеси используется импульсно-периодический разряд $[3-5,10]$. Импульсно-периодический разряд требует сравнительно простую конструкцию как разрядного устройства, так и самого источника питания газового разряда низкого давления, что делает подобные излучатели более дешевыми, а значит и более конкурентноспособными.

Важный интерес для научных исследований представляют аминокислоты, входящие в структуру живых организмов. Одной из 20 стандартных аминокислот, входящих в состав белка, является глутамин $\left(\mathrm{C}_{5} \mathrm{H}_{10} \mathrm{~N}_{2} \mathrm{O}_{3}\right)$. Также в русскоязычной научной литературе для названия молекулы используется термин „глютамин“. Исследование процессов, происходящих в биомолекулах, в частности в глутамине, на сегодня является актуальной задачей. Поэтому нами для экспериментальных исследований тоже была выбрана именно эта молекула. Структурную формулу глутамина можно представить следующим образом:<smiles>NC(=O)CCC(N)C(=O)O</smiles>

Схема. 
Авторами работы [7] были измерены оптические спектры излучения в диапазоне длин волн $250-520 \mathrm{~nm}$. Установлено, что в результате распада молекул глутамина наиболее эффективно образуются молекулярные эмиссии радикалов ОН и некоторых других молекулярных фрагментов и регистрируются возбужденные атомы водорода. Найдено, что энергии порогов возбуждения молекулярных эмиссий фрагментов молекул глутамина составляют $10-12 \mathrm{eV}$, в то время как для атомарных линий водорода не превышают $15 \mathrm{eV}$.

Данная работа посвящена изучению спектральных характеристик газового разряда в смесях паров глутамина с гелием (He-Glu) в спектральной области 200-850 nm. Подобного рода экспериментальные исследования представленной рабочей смеси были проведены нами впервые.

\section{2. Методика проведения экспериментов}

Для исследований рабочей смеси гелий-глутамин использован порошок глутамина производства фирмы Sigma Aldrich чистотой 99\%. Основные узлы экспериментальной установки, использованной для получения экспериментальных данных, описаны в работах [11-14]. Источник для получения излучения низкотемпературной плазмы был создан на основе газоразрядной трубки (ГРТ) из плавленого кварца внутренним диаметром $12 \mathrm{~mm}$ и расстоянием между электродами $25 \mathrm{~cm}$. Порошок глутамина белого цвета находился в самом газоразрядном устройстве, например, как показано в нашей работе [11]. В противоположных торцах ГРТ находятся герметично вклеенные коаксиальные медные электроды. Необходимое давление пара рабочей смеси в разрядной трубке обеспечивается нагреванием He-Glu исключительно за счет саморазогрева низкотемпературной плазмы.

Вывод излучения для анализа осуществлялся через торцевые кварцевые окна, которые пропускали 85\% излучения азотного лазера на длине волны $337 \mathrm{~nm}$. Исследование спектров люминесценции импульснопериодического разряда проводилось с помощью дифракционного монохроматора MS 7504i, построенного по горизонтальной оптической схеме Черни-Тернера с компенсацией астигматизма. Эта оптическая схема позволяет избежать повторного отражения излучения от дифракционных решеток. Регистрация черновых вариантов спектров излучения низкотемпературной плазмы паров смеси гелий-глутамин осуществлялась с использованием фоторегистрирующего детектора CCD-камеры HS 101H или фотоэлектронного умножителя R928 фирмы Hamamatsu с дифракционной решёткой 150 lines $/ \mathrm{mm}$ и выводом на персональный компьютер. Также нами в экспериментах использовались дифракционные решётки 2400, 1800 и 1200 lines $/ \mathrm{mm}$. Калибровка проводилось с использованием дейтериевой лампы ДДС-30 в УФ области спектра и вольфрамовой лампы накаливания СИ8-200У — в видимой области излучения.

Для возбуждения импульсно-периодического разряда в источнике излучения был использован генератор с тиратроном ТГИ2-500/20 (или ТГИ1-2000/35) в качестве коммутатора. Данный генератор позволял использовать частоту следования импульсов до $10 \mathrm{kHz}$ (длительность импульсов накачки в данных экспериментах не превышала нескольких $\mu \mathrm{s}$, как правило, до $2 \mu \mathrm{s}$ ) при зарядных напряжениях, не превышающих $10 \mathrm{kV}$, средний ток разряда не превышал $0.5 \mathrm{~A}$, а максимальная мощность, вкладываемая в газоразрядную плазму, $2.5 \mathrm{~kW}$. Режим резонансной перезарядки позволяет увеличить напряжение на накопительном конденсаторе до двух раз в сравнении с напряжением на выпрямителе. Откачка газоразрядного устройства осуществлялась форвакуумным насосом 3НВР-1Д. Напуск инертного газа гелия осуществлялся из дополнительного объёма. В результате саморазогрева температура ГРТ могла изменяться от комнатной до нескольких сотен градусов Цельсия. Контроль температуры рабочей смеси He-Glu осуществлялся с помощью градуированной платино-платинородиевой термопары, которая была плотно закреплена на внешней стороне разрядной трубки.

Более детально методика экспериментов и конструкция разрядного устройства описаны в работах [12-14].

\section{3. Люминесцентные характеристики низкотемпературной плазмы}

Спектр люминесценции низкотемпературной плазмы на основе смеси гелия с парами глутамина представлен на рис. 1. Условия, при которых были получены представленные экспериментальные данные, были близки к оптимальным. При данных условиях эксперимента излучение низкотемпературной газоразрядной плазмы определяют исключительно возбужденные молекулы азота $\left(\mathrm{N}_{2}^{*}\right)$, излучение принадлежит второй положительной системе (фиолетовое оттенение, достаточно узкие полосы с несколькими кантами), а именно электронному переходу $C^{3} \Pi_{u} \rightarrow B^{3} \Pi_{g}$ (длины волн основных максимумов приведены на самом рисунке). Как видно из рисунка, излучение молекулы гидроксила $\mathrm{OH}^{*}$ (спектральный переход $A^{2} \Sigma^{+} \rightarrow X^{2} \Pi$, с главным максимумом при $309 \mathrm{~nm}$, см. таблицу) практически незаметно на фоне люминесценции возбужденной молекулы азота $\mathrm{N}_{2}^{*}$. Спонтанное излучение возбужденных радикалов гидроксила $\mathrm{OH}\left(A^{2} \Sigma^{+}\right)$обусловлено их возникновением в результате реакций диссоциации карбоксильной (-COOH) группы молекулы глутамина. Стоит отметить, что энергия возбуждения электронного состояния $\mathrm{OH}\left(A^{2} \Sigma^{+}\right)$из состояния $\mathrm{OH}\left(X^{2} \Pi\right)$ составляет $4 \mathrm{eV}$. Радикал $\mathrm{OH}$, возникающий в результате диссоциации групп (-COOH), может соединяться с другими компонентами низкотемпературной плазмы. Поэтому на поверхности разрядного устройства могут создаваться 
кластерные соединения типа $(\mathrm{OH})_{m}$, которые достаточно устойчивы в условиях газовых разрядов низкого давления и почти не разлагаются на отдельные радикалы $\mathrm{OH}$. Возникновение подобных кластерных соединений ведет к уменьшению эффективности спонтанного излучения газоразрядной плазмы в исследуемой области спектра, на эти процессы уходит часть энергии в первую очередь от метастабильных атомов гелия.

Типичные спектры люминесценции импульсно-периодического разряда в смеси гелий-глутамин в диапазоне длин волн от 200 до $850 \mathrm{~nm}$ приведены на рис. 2 (спектр с учетом спектральной чувствительности системы регистрации). Условия получения представленных экспериментальных данных были одинаковыми и близкими к оптимальным. В УФ диапазоне спектра сосредоточено всего несколько десятков процентов общей мощности излучения газоразрядной низкотемпературной плазмы на основе паров глутамина. В самом начале (на протяжении нескольких десятков секунд) после включения электрического разряда при низких температурах ГРТ излучают преимущественно атомы гелия (переходы $3 s-2 p$, $3 d-2 p$ и $4 d-2 p$, которые вместе с излучением молекул азота придают розовый оттенок газовому разряду). Лишь при саморазогреве разрядной трубки (примерно от $50^{\circ} \mathrm{C}$ ) начинает появляться достаточно интенсивное излучение молекул азота в УФ области спектра при давлениях гелия, не превышающих 40 Torr (рис. 3,a). По мере прогрева рабочей смеси в эмиссионных спектрах полностью исчезают спектральные линии атомов гелия, быстро падает интенсивность излучения молекул азота. В то же время растет интенсивность полос молекул монооксида углерода, а именно перехода $B^{1} \Sigma \rightarrow A^{1} \Pi$ (система Ангстрема, одинарные канты с фиолетовым оттенением) с основными максимумами в видимой области при 451, 483, 520, $561 \mathrm{~nm}$ (таблица). Как вид-

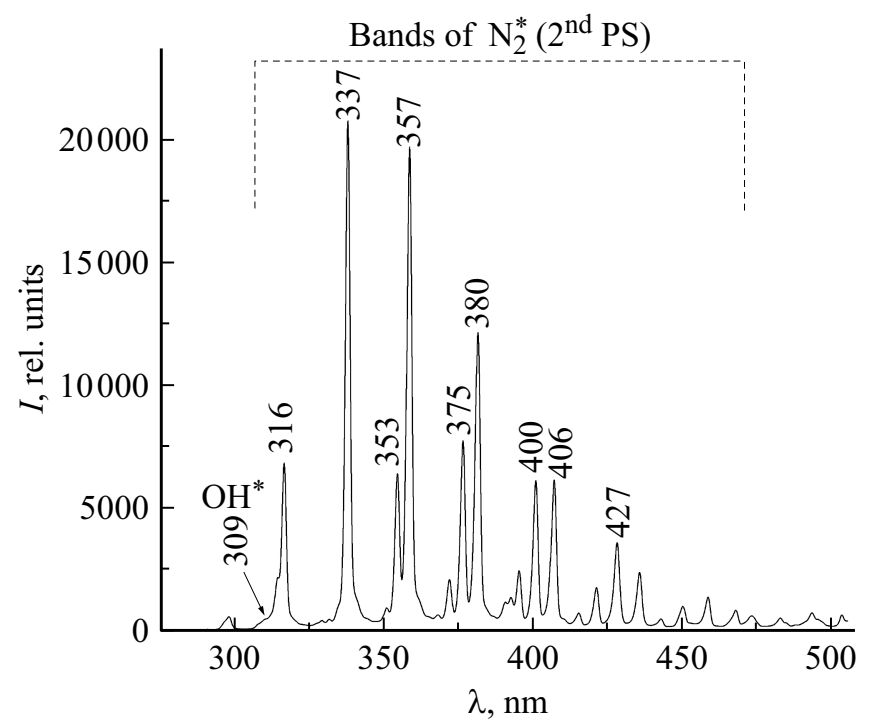

Рис. 1. Интегрированный во времени эмиссионный спектр излучения фрагментов смеси гелия с парами глутамина (при температуре ГРТ $\sim 80^{\circ} \mathrm{C}$ ) в области $250-500 \mathrm{~nm}$.
Основные эмиссии, наблюдаемые в импульсном разряде смеси гелий-глютамин

\begin{tabular}{c|c|l}
\hline $\begin{array}{c}\text { Длина волны, } \\
\mathrm{nm}\end{array}$ & Молекула & $\begin{array}{c}\text { Электронно-колебательный } \\
\text { переход }\end{array}$ \\
\hline 309 & $\mathrm{OH}$ & $a^{2} \sigma^{+}(v=0) \rightarrow X^{2} \Pi(v=0)$ \\
315.9 & $\mathrm{~N}_{2}$ & $C^{3} \Pi_{u}(v=1) \rightarrow B^{3} \Pi_{g}(v=0)$ \\
337.1 & $\mathrm{~N}_{2}$ & $C^{3} \Pi_{u}(v=0) \rightarrow B^{3} \Pi_{g}(v=0)$ \\
357.7 & $\mathrm{~N}_{2}$ & $C^{3} \Pi_{u}(v=0) \rightarrow B^{3} \Pi_{g}(v=1)$ \\
380.4 & $\mathrm{~N}_{2}$ & $C^{3} \Pi_{u}(v=0) \rightarrow B^{3} \Pi_{g}(v=2)$ \\
405.8 & $\mathrm{~N}_{2}$ & $C^{3} \Pi_{u}(v=0) \rightarrow B^{3} \Pi_{g}(v=3)$ \\
388.3 & $\mathrm{CN}$ & ${ }^{3} \Sigma(v=0) \rightarrow{ }^{2} \Sigma(v=0)$ \\
451 & $\mathrm{CO}$ & $B^{1} \Sigma(v=0) \rightarrow A^{1} \Pi(v=0)$ \\
483 & $\mathrm{CO}$ & $B^{1} \Sigma(v=0) \rightarrow A^{1} \Pi(v=1)$ \\
607.9 & $\mathrm{CO}$ & $B^{1} \Sigma(v=0) \rightarrow A^{1} \Pi(v=3)$ \\
629.9 & $\mathrm{CO}$ & $B^{1} \Sigma(v=1) \rightarrow A^{1} \Pi(v=6)$ \\
668.6 & $\mathrm{CO}$ & $a^{1}{ }^{3} \Sigma(v=4) \rightarrow a^{3} \Pi(v=0)$ \\
755.2 & $\mathrm{CO}$ & $a^{3} \Sigma(v=4) \rightarrow a^{1} \Pi(v=1)$
\end{tabular}

но из рис. $3, b$, при давлениях до 40 Torr излучение молекул СО тоже будет максимальным. Растет также интенсивность спектрального перехода $a^{\prime}{ }^{3} \Sigma \rightarrow a^{3} \Pi$ [15] (полосы Асунди, с характерной сложной структурой с красным оттенением и несколькими кантами) с главными максимумами при 608, 626, 632, 660, 675, 716, 762 и $775 \mathrm{~nm}$, при этом цвет наблюдаемого излучения разряда становится беловатым.

Наибольший вклад в общую мощность УФ излучения разряда вносят молекулы азота. Их излучение так же, как и на рис. 1, принадлежит второй положительной системе, а именно электронному переходу $C^{3} \Pi_{u} \rightarrow B^{3} \Pi_{g}$ с основными максимумами при 316,357 , 375 и $380 \mathrm{~nm}$ (таблица). Таким образом, анализ структуры спектра излучения низкотемпературной плазмы импульсно-периодического разряда показывает, что в условиях эксперимента в излучении продуктов распада молекул глутамина доминируют возбужденные молекулы азота и монооксида углерода. Возможно, также присутствует одна полоса фиолетовой системы молекулы циана $\mathrm{CN}^{*}$, а именно спектральный переход ${ }^{2} \Sigma \rightarrow{ }^{2} \Sigma$ (энергии возбуждения состояния $B^{2} \Sigma^{+}$молекулы циана $\sim 3 \mathrm{eV})$ с одним главным максимумом при $388.3 \mathrm{~nm}$ (возможно, что эта полоса молекулы циана перекрывается с люминесценцией молекулы монооксида углерода с главным максимумом при $\sim 389 \mathrm{~nm}$, спектральный переход $C^{1} \Sigma \rightarrow A^{1} \Pi[16]$, система Герцберга, тоже с фиолетовым оттенением). Две другие интенсивные серии фиолетовой системы возбужденной молекулы циана менее отчетливы, возможно, они подавлены излучением возбужденных молекул азота $\mathrm{N}_{2}^{*}$ и сливаются с переходом $C^{3} \Pi_{u} \rightarrow B^{3} \Pi_{g}$.

Пороговое значение температуры стенки ГРТ, при котором эмиссия перехода $C^{3} \Pi_{u} \rightarrow B{ }^{3} \Pi_{g}$ возбужденных молекул азота (энергия возбуждения состояния молекулярного азота $\left.C^{3} \Pi_{u} \sim 11 \mathrm{eV}\right)$ в УФ области спектра была почти максимальной, составляло около $80^{\circ} \mathrm{C}$. 

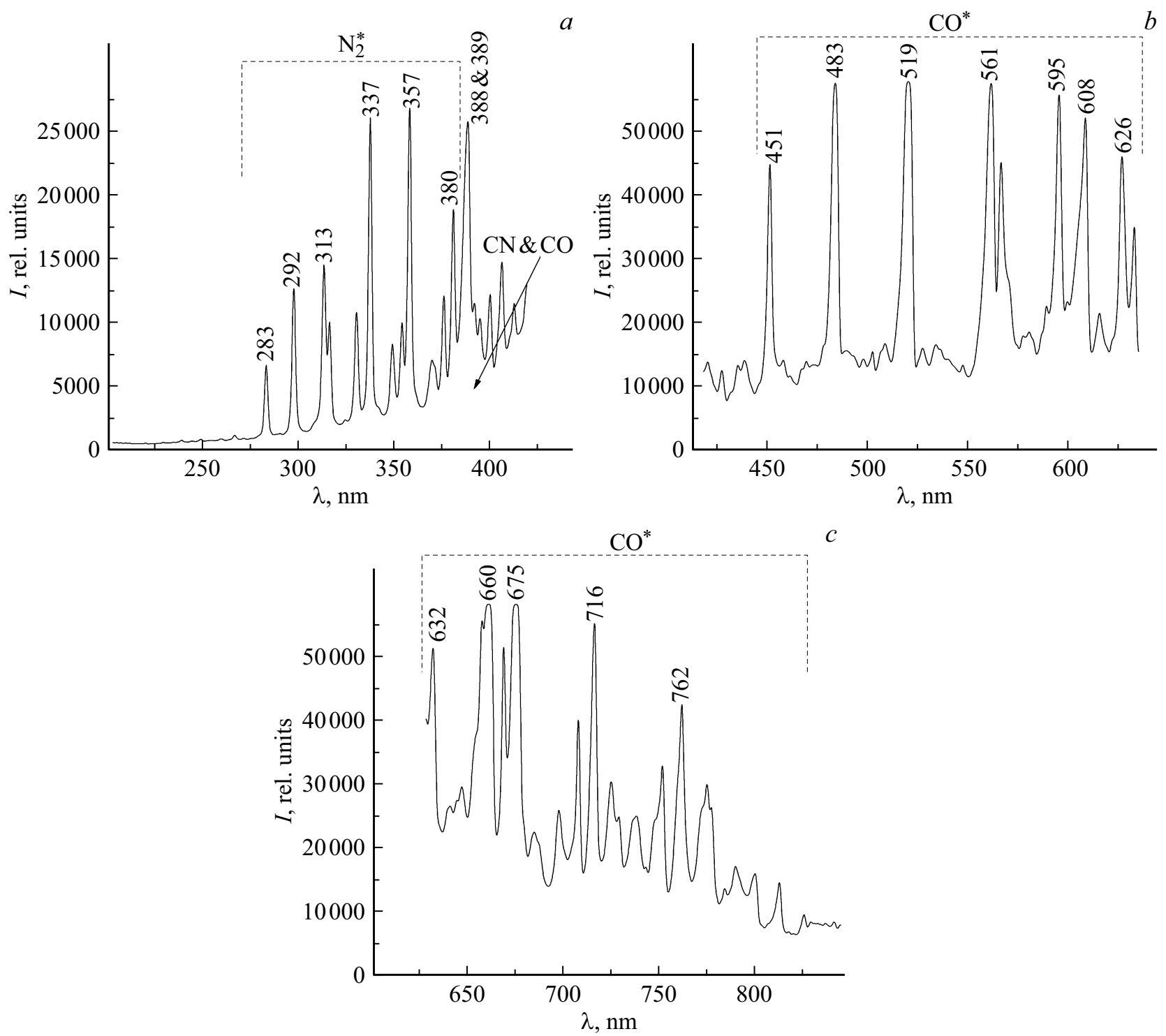

Рис. 2. Спектры люминесценции низкотемпературной плазмы в смеси He-Glu.

При дальнейшем увеличении температуры наблюдался резкий рост интенсивности полос молекул монооксида углерода. Отклонение температуры на несколько десятков ${ }^{\circ} \mathrm{C}$ от оптимального значения в сторону больших или меньших значений приводит к значительному снижению интенсивности излучения, что свидетельствует о понижении температуры электронов низкотемпературной плазмы. Это, в свою очередь, приводит к снижению эффективности образования возбужденных атомов гелия $\mathrm{He}^{*}$ (метастабильные состояния $1 s 2 s^{3} S_{1}$ и $1 s 2{ }^{1} S_{0}$, для формирования которых нужны энергии $\sim 20 \mathrm{eV}$ ), которые являются необходимыми реагентами для получения излучающих молекул азота $\mathrm{N}_{2}$ и монооксида углерода СО, возбужденные состояния которых приведены выше.

Функциональная зависимость интенсивности ультрафиолетового излучения молекул азота от частоты воз- буждения импульсно-периодического разряда приведена на рис. 4. Видно, что при увеличении напряжения на выпрямителе блока возбуждения разряда до значений $\sim 3 \mathrm{kV}$ идет резкое увеличение эффективности образования рабочих молекул, фрагментов молекулы глутамина. Очевидно, что усиление электрического поля приводит к большему энерговкладу в низкотемпературную плазму и увеличивает температуру электронов импульсно-периодического разряда. Поэтому значительный рост интенсивности излучения обусловлен увеличением эффективности возбуждения метастабильных уровней атомов гелия, которые передают энергию молекулам глутамина и их фрагментам, появляющимся в результате диссоциации карбоксильной и аминогрупп. На рисунке видно, что оптимальными для наших экспериментов являются частоты $\sim 7 \mathrm{kHz}$, поскольку интенсивность 

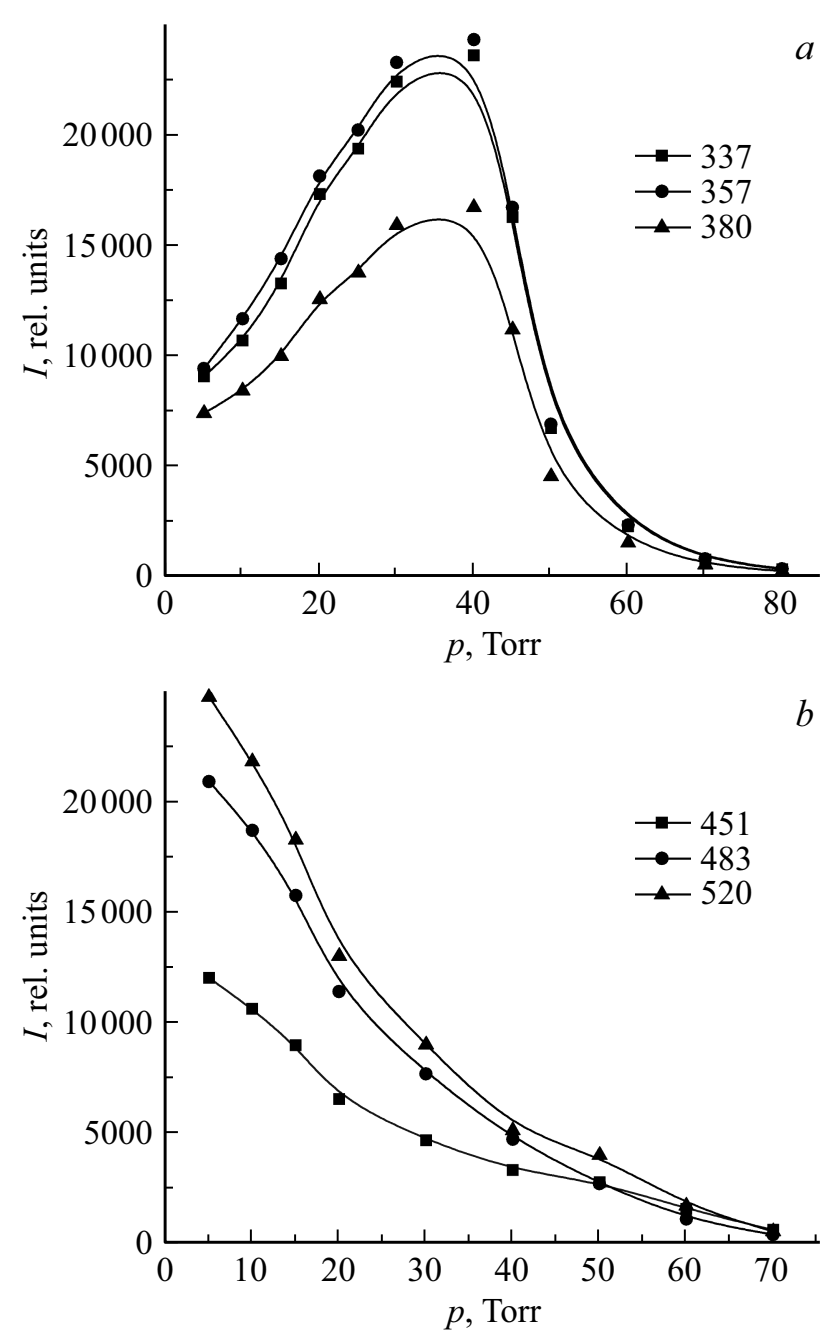

Рис. 3. Зависимость интенсивности излучения отдельных переходов молекул азота $(a)$ и монооксида углерода $(b)$ от давления гелия.

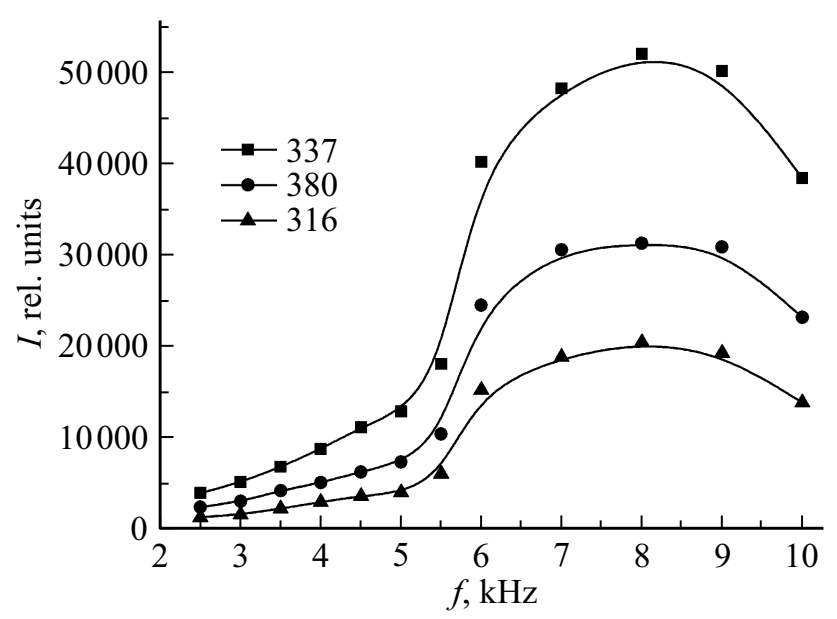

Рис. 4. Зависимость интенсивности излучения перехода $C^{3} \Pi_{u} \rightarrow B^{3} \Pi_{g} \quad$ (с главными максимумами на 316,337 и $380 \mathrm{~nm}$ ) молекул азота от частоты на выпрямителе. получаемого излучения молекул фрагментов глутамина будет максимальной.

Спектры люминесценции и другие характеристики плазмы регистрировались при близких к оптимальным значениях параметров (установлены нами в результате экспериментов) продольного импульснопериодического разряда: напряжение на выпрямителе было равным $\sim 3 \mathrm{kV}$, частота следования импульсов возбуждения электрического разряда составляла $\sim 7 \mathrm{kHz}$, давление паров рабочей смеси гелий-глутамин в разрядной трубке поддерживалось на уровне нескольких десятков Torr, температура внешней стенки ГРТ не превышала $140^{\circ} \mathrm{C}$.

Как известно, максимальная длина связи соответствует наименьшей энергии данной связи, что приводит к ее разрыву и образованию фрагментов молекулы. Поскольку наименьшую энергию имеют связи C-C, N-C, $\mathrm{C}-\mathrm{O}$, то происходит разрыв данных связей, что приводит к фрагментации молекулы глутамина и диссоциации карбоксильной $(-\mathrm{COOH})$ и аминогруппы $\left(-\mathrm{NH}_{2}\right)$ в результате чего и появляются молекулы $\mathrm{N}_{2}, \mathrm{CO}, \mathrm{CN}$ в возбужденном состоянии.

Таким образом, в полученной нами низкотемпературной плазме образование излучающих молекул происходит за счет фрагментации молекул глутамина и последующей диссоциации карбоксильной $(-\mathrm{COOH})$ и амино $\left(-\mathrm{NH}_{2}\right)$ групп на молекулы монооксида углерода, азота, гидроксила и циана, которые в свою очередь эффективно возбуждаются при взаимодействии с метастабильными атомами гелия. Основные реакции, которые приводят к люминесценции, наблюдаемой в экспериментах, можно представить следующим образом:

$$
\begin{gathered}
e^{*}+\mathrm{He} \rightarrow \mathrm{He}\left(1 s 2 s^{3} S_{1}\right)^{*}+e, \\
e^{*}+\mathrm{He} \rightarrow \mathrm{He}\left(1 s 2 s^{1} S_{0}\right)^{*}+e, \\
\mathrm{He}^{*}+\mathrm{C}_{5} \mathrm{H}_{10} \mathrm{~N}_{2} \mathrm{O}_{3} \rightarrow \mathrm{C}_{4} \mathrm{H}_{9} \mathrm{~N}_{2} \mathrm{O}+\mathrm{COOH}+\mathrm{He}, \\
e^{*}+\mathrm{C}_{5} \mathrm{H}_{10} \mathrm{~N}_{2} \mathrm{O}_{3} \rightarrow \mathrm{C}_{4} \mathrm{H}_{8} \mathrm{~N}_{2}+\mathrm{COOH}+\mathrm{OH}+\mathrm{H} \\
\mathrm{He}^{*}+\mathrm{C}_{5} \mathrm{H}_{10} \mathrm{~N}_{2} \mathrm{O}_{3} \rightarrow \mathrm{C}_{2} \mathrm{H}_{9} \mathrm{~N}_{2} \mathrm{O}_{3}+\mathrm{OH}+\mathrm{He},
\end{gathered}
$$$$
\mathrm{He}^{*}+\mathrm{C}_{5} \mathrm{H}_{10} \mathrm{~N}_{2} \mathrm{O}_{3} \rightarrow \mathrm{C}_{4} \mathrm{H}_{8} \mathrm{~N}_{2}+\mathrm{COOH}+\mathrm{OH}+\mathrm{He},
$$$$
\mathrm{He}^{*}+\mathrm{Glu} \rightarrow
$$

(продукты фрагментации Glu $\left.=\mathrm{N}_{2}, \mathrm{CN}, \mathrm{CO}, \mathrm{OH}\right)+\mathrm{He}$,

$$
\begin{gathered}
\mathrm{He}^{*}+\mathrm{N}_{2} \rightarrow \mathrm{N}_{2}^{*}\left(C^{3} \Pi_{u}\right)+\mathrm{He}, \\
\mathrm{N}_{2}^{*}\left(C^{3} \Pi_{u}\right) \rightarrow \mathrm{N}_{2}\left(B^{3} \Pi_{g}\right)+h v, \\
\mathrm{He}^{*}+\mathrm{OH} \rightarrow \mathrm{OH}\left(A^{2} \Sigma^{+}\right)+\mathrm{He}, \\
\mathrm{OH}\left(A^{2} \Sigma^{+}\right) \rightarrow \mathrm{OH}\left(X^{2} \Pi\right)+h v_{1}, \\
\mathrm{He}^{*}+\mathrm{CN} \rightarrow \mathrm{CN}^{*}+\mathrm{He}, \\
\mathrm{He}^{*}+\mathrm{CO} \rightarrow \mathrm{CO}^{*}+\mathrm{He}, \\
\mathrm{CO}\left(B^{1} \Sigma\right) \rightarrow \mathrm{CO}\left(A^{1} \Pi\right)+h v_{2}, \\
\mathrm{CO}\left(a^{\prime 3} \Sigma\right) \rightarrow \mathrm{CO}\left(a^{3} \Pi\right)+h v_{3} .
\end{gathered}
$$

Отдельно стоит отметить сравнительно высокую эффективность передачи энергии от возбужденных атомов 
гелия молекулам монооксида углерода, интенсивность излучения которых значительно выше (при условиях нашего эксперимента примерно в 2 раза), чем молекул азота, хотя и излучают они в разных областях спектра.

\section{Выводы}

Впервые экспериментально исследованы и проанализированы спектры люминесценции смеси Не- $\mathrm{C}_{5} \mathrm{H}_{10} \mathrm{~N}_{2} \mathrm{O}_{3}$ в низкотемпературной плазме продольного импульсно-периодического разряда в спектральном диапазоне 200-850 nm.

Установлено, что использование в качестве доноров молекул глутамина позволяет получить интенсивные полосы УФ излучения фрагментов глутамина, а именно молекул азота $\mathrm{N}_{2}\left(C^{3} \Pi_{u} \rightarrow B^{3} \Pi_{g}\right)$ и монооксидов углерода $\mathrm{CO}^{*}\left(B^{1} \Sigma \rightarrow A^{1} \Pi\right)$ в видимой и ближней инфракрасной областях, возникающих в результате диссоциации амино- $\left(-\mathrm{NH}_{2}\right)$ и карбоксильной $(-\mathrm{COOH})$ групп. Представлены основные реакции, приводящие к излучению этих молекул в данном спектральном интервале.

Наибольший выход полученной спонтанной люминесценции молекул фрагментов глутамина достигается при оптимальных условиях экспериментов и температуре стенок ГРТ, не превышающей $140^{\circ} \mathrm{C}$.

\section{Благодарности}

Выражаю благодарность инженеру К.П. Поповичу за помощь в получении экспериментальных данных.

\section{Конфликт интересов}

Автор заявляет, что у него нет конфликта интересов.

\section{Список литературы}

[1] Heneral A.A., Avtaeva S.V. // Opt. Spectrosc. 2017. V. 123. P. 531. https://doi.org/10.1134/S0030400X17100071

[2] General A.A., Kel'man V.A., Zhmenyak Yu.V., Shpenik Yu.O., Klenovskii M.S. // Opt. Spectrosc. 2013. V. 114. N 1. P. 25. https://doi.org/10.1134/S0030400X13010104

[3] Ivanov A. // Opt. Spectrosc. 2019. V. 126. P. 167. https://doi.org/10.1134/S0030400X1903007X

[4] Ivanov V.A., Skoblo Yu.E. // Opt. Spectrosc. 2019. V. 127. P. 820. https://doi.org/10.1134/S0030400X19110110

[5] Ivanov V.A., Petrovskaya A.S., Skoblo Yu.E. // Opt. Spectrosc. 2017. V. 123. P. 692. https://doi.org/10.1134/S0030400X17110091

[6] Heneral A.A. // Opt. Spectrosc. 2019. V. 127. N 5. P. 778. https://doi.org/10.1134/S0030400X19110092

[7] Erdevdi N.M., Bulhakova A.I., Shpenik O.B., Zavilopulo A.N. // Techn. Phys. Lett. 2020. V. 46. P. 815. https://doi.org/10.1134/S1063785020080209

[8] Migovich M.I., Kel'man V.A. // Opt. Spectrosc. 2016. V. 121. P. 62. https://doi.org/10.1134/S0030400X16070134
[9] General A.A., Migovich M.I., Kelman V.A., Zhmenyak Yu.V., Zvenigorodsky V.V. // J. Appl. Spectrosc. 2016. V. 82. P. 970. https://doi.org/10.1007/s10812-016-0213-5

[10] Heneral A.A., Zhmenyak Y.V. // J. Appl. Spectrosc. 2018. V. 85. P. 79. https://doi.org/10.1007/s10812-018-0615-7

[11] Avtaeva S.V., Heneral A.A. // Plasma Chemistry and Plasma Processing. 2020. V. 40. P. 839. https://doi.org/10.1007/s11090-020-10067-1

[12] Heneral A.A., Avtaeva S.V. // J. Phys. D. 2017. V. 50. P. 495202. https://doi.org/10.1088/1361-6463/aa93bb

[13] Avtaeva S.V., General A.A., Kelman V.A. // J. Phys. D. 2010. V. 43. P. 315201. https://doi.org/10.1088/00223727/43/31/315201

[14] Heneral A.A., Avtaeva S.V. // J. Phys. D. 2020. V. 53. P. 195201. https://doi.org/10.1088/1361-6463/ab7354

[15] Asundi R.K. // Proc. Roy. Soc. 1929. V. 124. P. 277.

[16] Duffendack O.S., Fox G.W. // Astrophys. J. 1927. V. 65. P. 214. 